\title{
Removal of $\mathrm{Pb}$ (II) ions in the aqueous solution by photo-Fenton method
}

\author{
Wahyuni E.T.*, Siswanta D., Kunarti E.S., Supraba D. and Budiraharjo S. \\ Chemistry Department, Faculty of Mathematic and Natural Sciences, Gadjah Mada University, Yogyakarta, Indonesia \\ Received: 01/11/2018, Accepted: 12/02/2019, Available online: 15/02/2019 \\ *to whom all correspondence should be addressed: e-mail: endang_triw@ugm.ac.id \\ https://doi.org/10.30955/gnj.002936
}

\begin{abstract}
Photo-Fenton for decreasing concentration of $\mathrm{Pb}$ (II) ions in the aqueous solution is systematically studied. The photo-Fenton process was carried out by batch technique, under UV light. The influences of the process operating parameters were evaluated. The results of the research demonstrated that by photo-Fenton process, the concentration of $\mathrm{Pb}$ (II) ions in the aqueous solution can be decreased, that may be through oxidation mechanism by $\mathrm{OH}$ radicals. The decrease is found to be dictated by $\mathrm{Fe}^{2+}$ and $\mathrm{H}_{2} \mathrm{O}_{2}$ concentrations, as well as by the $\mathrm{pH}$ and the irradiation time. For $25 \mathrm{mg} / \mathrm{L}$ of $\mathrm{Pb}(\mathrm{II})$ in the $100 \mathrm{~mL}$ solution, the optimum condition of the oxidation is obtained to be 10 mmole of $\mathrm{Fe}^{2+}, 200$ mmole of $\mathrm{H}_{2} \mathrm{O}_{2}, \mathrm{pH}$ 3 , and 90 mins of the reaction time. It is also confirmed that the oxidation of $\mathrm{Pb}^{2+}$ by $\mathrm{OH}$ radical has formed the undissolved $\mathrm{PbO}_{2}$, that is less toxic and easier to be handled. The oxidation well fits to the first order reaction with the rate of the reaction is as much as $0.07 \mathrm{mmole} / \mathrm{min}$.
\end{abstract}

Keywords: Photo-Fenton, $\mathrm{Pb}^{2+}$, oxidation, removal.

\section{Introduction}

The release of heavy metals into wastewater through human and industrial activities has become a major problem both to humans and aquatic lives. Among heavy metals, lead $(\mathrm{Pb})$ is ranked in the 5 main hazardous heavy metals (Harrison and Laxen, 1981), that has harmful effects on human health, especially for children (Harrison, and Laxen, 1981; NRC Committee on Lead in the Human Environment, 1980). Further, high lead level has been reported to cause organs and brain damaged, and mental retardation (NRC Committee on Lead in the Human Environment, 1980). Lead as $\mathrm{Pb}^{2+}$ is frequently found in the industrial wastewater of manufactures of paint, battery, and pigment, and metal plating activity (NRC Committee on Lead in the Human Environment, 1980).

To remove of $\mathrm{Pb}^{2+}$ ions in the water, adsorption (Yao et al., 2016; Asuquo et al., 2017; Mahmoud et al., 2016; Soliman et al., 2016) and biosorption methods (Chen et al., 2010; Yuvaraja et al., 2014; Ayoub et al., 2013) have been frequently attempted. Those methods were found to be simple and effective (Yao et al., 2016; Asuquo et al., 2017; Mahmoud et al., 2016; Soliman et al., 2016; Chen et al., 2010; Yuvaraja et al., 2014; Ayoub et al., 2013), however the toxic property of the $\mathrm{Pb}^{2+}$ remains existed. Accordingly, when the adsorbents have been exhausted with the toxic $\mathrm{Pb}^{2+}$, they become solid toxic waste. This creates new environmental problem that needs further treatment.

It has been reported an effort to covert the toxic $\mathrm{Pb}^{2+}$ into the less toxic $\mathrm{PbO}_{2}$ through oxidation reaction, that is called as photocatalytic oxidation (Tanaka et al., 1986; Chen and Ray, 2001; Wahyuni et al., 2015). In this method, $\mathrm{TiO}_{2}$ photocatalyst in water media is exposed with UV light that results in $\mathrm{OH}$ radical, as presented by reactions (1) and (2).

$$
\begin{aligned}
& \mathrm{TiO}_{2}+\text { light } \rightarrow \mathrm{TiO}_{2}\left(\mathrm{e}+\mathrm{h}^{+}\right) \\
& \mathrm{H}_{2} \mathrm{O}+\mathrm{h}^{+} \rightarrow \mathrm{H}^{+}+{ }^{\circ} \mathrm{OH} \\
& \mathrm{Pb}^{2+}+2^{\cdot} \mathrm{OH} \rightarrow \mathrm{PbO}_{2}+2 \mathrm{H}^{+}
\end{aligned}
$$

The hydroxyl radical $\left({ }^{\circ} \mathrm{OH}\right)$ acts as a strong oxidizing agent assigned by standard oxidation potential $\left(\mathrm{E}^{\circ}\right)$ as much as $2.8 \mathrm{~V}$, that is higher than other oxidants such as ozone ( $\left.\mathrm{E}^{\circ}=2.0 \mathrm{~V}\right)$ and $\mathrm{H}_{2} \mathrm{O}_{2}\left(\mathrm{E}^{\circ}=1.8 \mathrm{~V}\right)$ (Fujishima et al., 2000). The high strength of the hydroxyl radicals ( $\left.{ }^{\circ} \mathrm{OH}\right)$ can induce $\mathrm{Pb}^{2+}$ oxidation (Tanaka et al., 1986; Chen and Ray, 2001; Wahyuni et al., 2015), as illustrated by reaction (3), as well as degrade a large number of organic compounds (Reza et al., 2017; Ajmal et al., 2014; Dariani et al., 2016; Zuo et al., 2014; Gautam et al., 2016; Shukla et al., 2009; ChoquetteLabbé et al., 2014; Grabowska et al., 2012; Turki et al., 2015) effectively. However, due to the heterogeneous system, the photocatalysis process faces light entering inhibition when large dose of the $\mathrm{TiO}_{2}$ powder is used (Reza et al., 2017; Dariani et al., 2016; Gautam et al., 2016), leading to the less effective photooxidation.

There is a homogeneous oxidation method that also provides $\mathrm{OH}$ radicals called photo-Fenton. Photo-Fenton method involves the use of Fenton's reagent, that is a combination of $\mathrm{Fe}^{2+}$ and $\mathrm{H}_{2} \mathrm{O}_{2}$, with UV light exposure (Babuponnusami and Muthukumar, 2014; Joseph and 
Katoch, 2016; Kavitha and Palanivelu, 2004, 2005; Huang et al., 2010; Kusi et al., 2006; Tony and Bedri, 2014; Zazouli et al., 2012; Azhdarpoor et al., 2015; Wahyuni et al., 2016; Shaban et al., 2017; Çiner, 2017; Ali and Ameta, 2013). In this process, $\mathrm{H}_{2} \mathrm{O}_{2}$ is decomposed catalytically by $\mathrm{Fe}^{2+}$ at acidic $\mathrm{pH}$, yielding hydroxide ion $\left(\mathrm{OH}^{-}\right)$and hydroxyl radical ( $\mathrm{OH}$ ) (reaction 4). While the $\mathrm{Fe}^{2+}$ ion is transformed into $\mathrm{Fe}^{3+}$ ions (reaction 5) that can further reacts with hydroxide ion $\left(\mathrm{OH}^{-}\right)$to form hydroxylated ferric ions $\left(\mathrm{FeOH}^{2+}\right.$ ) (reaction 6). In the presence of UV light, $\mathrm{H}_{2} \mathrm{O}_{2}$ is also decomposed into $\mathrm{OH}$ radicals (reaction 7) (Kavitha and Palanivelu, 2004). It is clear that a lot number of $\mathrm{OH}$ radicals can be provided, that promote more effective oxidation. Additionally, since the chemicals exist as dissolved species, the light entering into the solution is not screened, that should result in the high photooxidation.

$$
\begin{aligned}
& \mathrm{Fe}^{2+}+\mathrm{H}_{2} \mathrm{O}_{2} \rightarrow \mathrm{Fe}^{3+}+\mathrm{OH}^{-}+\mathrm{OH}^{-} \\
& \mathrm{Fe}^{3+}+\mathrm{H}_{2} \mathrm{O}_{2} \rightarrow \mathrm{Fe}^{2+}+2 \cdot \mathrm{OH} \\
& \mathrm{Fe}^{3+}+\mathrm{OH}^{-} \rightarrow \mathrm{Fe}(\mathrm{OH})^{2+} \\
& \mathrm{H}_{2} \mathrm{O}_{2}+\mathrm{UV} \rightarrow 2 \cdot \mathrm{OH}
\end{aligned}
$$

Based on the ability in providing $\mathrm{OH}$ radicals, photoFenton method has been intensively studied for removal of wide range of organic pollutants including phenols (Kavitha and Palanivelu, 2004; Huang et al., 2010; Kusi et al., 2006), nitrophenol (Kavitha and Palanivelu, 2005), car wash wastewater (Tony and Bedri, 2014), and organic compounds in leachates (Joseph and Katoch, 2016; Zazouli et al., 2012) and in sludge (Azhdarpoor et al., 2015), as well as for surfactant in the laundry waste water (Wahyuni et al., 2016), and dyes in water (Shaban et al., 2017; Çiner, 2017; Ali and Ameta, 2013). However, so far there is no study of photo-Fenton method to decline the concentration of $\mathrm{Pb}(\mathrm{II})$ ion in the water through oxidation mechanism that has been reported.

Under the circumstance, in this present paper, photooxidation of $\mathrm{Pb}(\mathrm{II})$ by the use of Fenton's reagent assisted with UV light is addressed. The oxidation power of Fenton reagent depends very much on the operating parameters, including the initial substrate concentration, $\mathrm{Fe}^{2+}$ concentration, $\mathrm{H}_{2} \mathrm{O}_{2}$ concentration, $\mathrm{Fe}^{2+} / \mathrm{H}_{2} \mathrm{O}_{2}$ mole ratio, $\mathrm{pH}$ and process time (Babuponnusami and Muthukumar, 2014). Therefore, it is necessary to find the optimal process parameters through laboratory treatability tests.

\section{Experiment}

\subsection{Chemicals}

The chemicals used were ferrous sulfate, hydrogen peroxide $30 \% \mathrm{v} / \mathrm{v}$, and lead nitrate with analytical grade that were purchased from E. Merck and were used as received. The aqueous solutions were prepared by using twice distilled water. Sodium hydroxide and hydrochloric acid received from Aldrich, were used for adjusting the $\mathrm{pH}$ of the solutions.

\subsection{Photo-Fenton process}

All experiments were carried out in duplicate and batch technique. A $250 \mathrm{~mL}$ Beaker glass was filled with $100 \mathrm{~mL}$ of solution containing $10 \mathrm{mg} / \mathrm{L} \mathrm{Pb}^{2+}, \mathrm{Fe}^{2+} 10 \mathrm{mmole} / \mathrm{L}$ and $\mathrm{H}_{2} \mathrm{O}_{2} 200 \mathrm{mmole} / \mathrm{L}$. The beaker glass was placed in the photoprocess apparatus, as illustrated by Figure 1, that was equipped with UV lamp with $250-350 \mathrm{~nm}$ of the wavelength. Then the UV lamp was turned on to start the photo-process, and the process was proceeded for 90 mins, that was accompanied by magnetically stirring. After a period of time as desired, the reaction was quit and the light brown turbid solution was formed in the solution. By filtration of the turbid solution through Whatman 42 paper filter, the clear solution was obtained.

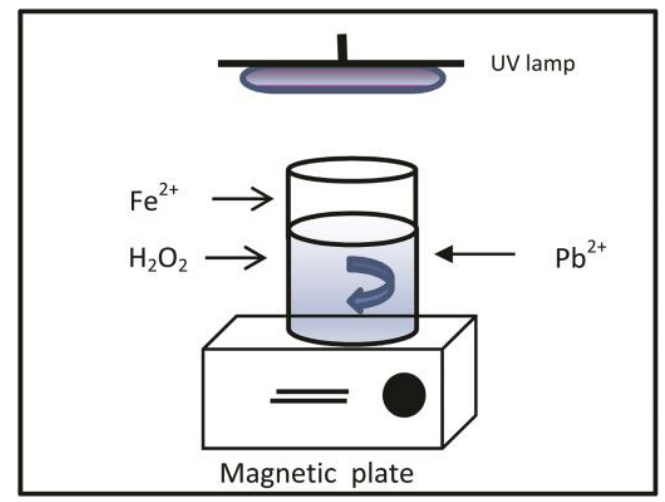

Figure 1. The simplified schematic diagram of a lab-scale for photo-Fenton process

The solid on the paper filter was dried at $110^{\circ} \mathrm{C}$ for $2 \mathrm{~h}$, and then it was analyzed by SEM-EDX instrument to identify its chemical composition. Meanwhile the solution was analyzed by using GBC type-AAS to determine the concentrations of $\mathrm{Pb}$ (II) left in the solution. The amount of $\mathrm{Pb}^{2+}$ removal is calculated by using formula below:

$$
\frac{\mathrm{Co}-\mathrm{Cl}}{\mathrm{Co}} \times 100 \%
$$

$\mathrm{Co}$ : the initial concentration of $\mathrm{Pb}$ (II) in the solution, $\mathrm{Cl}$ : the concentration of $\mathrm{Pb}$ (II) left in the solution.

The same procedure was repeated with various of $\mathrm{Fe}^{2+}$ and $\mathrm{H}_{2} \mathrm{O}_{2}$ concentrations, the irradiation time, system $\mathrm{pH}$, and the initial concentration of $\mathrm{Pb}(\mathrm{I})$. When one operating variable was varied, the other variables were adjusted to be constant.

\section{Results and Discussion}

\subsection{The influence of $\mathrm{Fe}^{2+}$ concentration}

The amount of $\mathrm{Fe}^{2+}$ is one of the primary parameters that influences the effectiveness of the photo-Fenton process (Kavitha and Palanivelu, 2004; Huang et al., 2010). In Figure 2. the influence of $\mathrm{Fe}^{2+}$ concentration on the effectiveness of the photo-Fenton process is displayed $\left(\mathrm{H}_{2} \mathrm{O}_{2}=200 \mathrm{mmol} / \mathrm{L}, \mathrm{pH}=3\right.$, time $\left.=90 \mathrm{mins}\right)$. It is observed that the increase of the $\mathrm{Fe}^{2+}$ concentration promotes the removal of $\mathrm{Pb}^{2+}$ ion up to reach the maximum level. Increasing $\mathrm{Fe}^{2+}$ concentration provides more amount of $\mathrm{Fe}^{2+}$ ions in the solution, that results in the higher amount of the hydroxyl radical, as described by reaction (4). This explains the fact that higher removal of $\mathrm{Pb}(\mathrm{II})$ is observed. 
The negative effect on the removal of $\mathrm{Pb}$ (II) appears when the concentration of $\mathrm{Fe}^{2+}$ is more than the optimum level. The excessive $\mathrm{Fe}^{2+}$ ion produces larger amount of $\mathrm{Fe}^{3+}$ ions (reaction 4) that further allows them to react with hydroxide ions formed from reaction (4), to form $\mathrm{Fe}(\mathrm{OH})_{3}$ precipitate, as seen in reaction (8) (Kavitha and Palanivelu, 2004; Huang et al., 2010).

$$
\mathrm{Fe}^{3+}+3 \mathrm{OH}^{-} \rightarrow \mathrm{Fe}(\mathrm{OH})_{3}
$$

The precipitate formation creates turbid solution that can inhibit the light entering into the solution (Babuponnusami and Muthukumar, 2014; Joseph and Katoch, 2016; Kavitha and Palanivelu, 2004; Huang et al., 2010; Kusi et al., 2006). The effect of this situation is a decrease in $\mathrm{OH}$ radical formation, that further diminishes of the $\mathrm{Pb}$ (II) removal. In addition, the precipitate can also further contribute to a significant increase in total dissolved solids (TDS), that requires further treatment of the effluent before its discharge to the receiving water. This finding is in a good agreement with the previous observations elsewhere (Joseph and Katoch, 2016; Kavitha and Palanivelu, 2004; Huang et al., 2010; Tony and Bedri, 2014; Azhdarpoor et al., 2015; Wahyuni et al., 2016; Çiner, 2017; Ali and Ameta, 2013).

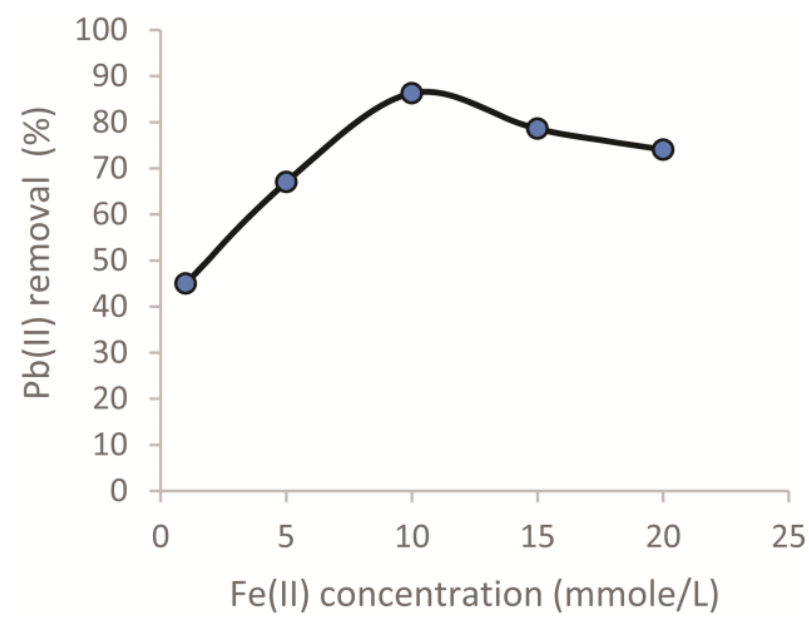

Figure 2. The influence of Fe(II) concentration on the removal of $\mathrm{Pb}^{(I I)}$ in the solution

The decrease of $\mathrm{Pb}$ (II) concentration can be caused by 2 possible reactions, that are reduction of the dissolved $\mathrm{Pb}^{2+}$ into undissolved $\mathrm{Pb}^{0}$, or oxidation of the dissolved $\mathrm{Pb}^{2+}$ into $\mathrm{Pb}(\mathrm{IV})$ formed as the undissolved $\mathrm{PbO}_{2}$ (Harrison and Laxen, 1981). The reduction of $\mathrm{Pb}^{2+}$ into $\mathrm{Pb}^{0}$ is impossible thermodynamically (Harrison and Laxen, 1981), so that the diminishing concentration by oxidation of $\mathrm{Pb}(\mathrm{II})$ by $\mathrm{OH}$ radicals (reaction 3 ) is favored, to form the solid $\mathrm{PbO}_{2}$. The same result of the solid $\mathrm{PbO}_{2}$ has also been obtained from the photopoxidation of $\mathrm{Pb}(\mathrm{II})$ ion by $\mathrm{OH}$ radicals that was provided by $\mathrm{TiO}_{2}$ under exposure of UV light (Tanaka et al., 1986). Furthermore, in this research, during the photo-Fenton process, light brown solid was observed.
To find out the compounds in the light brown solid, the solid was also analyzed by SEM-EDX instrument, and the result is presented as Figure 3 . From the figure and the table along with, it is informed that $\mathrm{Fe}, \mathrm{Pb}, \mathrm{S}$ and $O$ elements are existed in the solid. The elements respectively may represent $\mathrm{Fe}(\mathrm{OH})_{3}$ (brown colored), $\mathrm{PbO}_{2}$, and $\mathrm{SO}_{4}$ (from $\mathrm{FeSO}_{4}$ reagent as source of $\mathrm{Fe}^{2+}$ ) compounds. It is confirmed that $\mathrm{Pb}$ (II) has been oxidized into $\mathrm{PbO}_{2}$ with relatively low amount. The low amount of $\mathrm{PbO}_{2}$ product was resulted form the low the initial concentration of $\mathrm{Pb}(\mathrm{II})$, that was $10 \mathrm{mg} / \mathrm{L}$ in $100 \mathrm{~mL}$ solution.

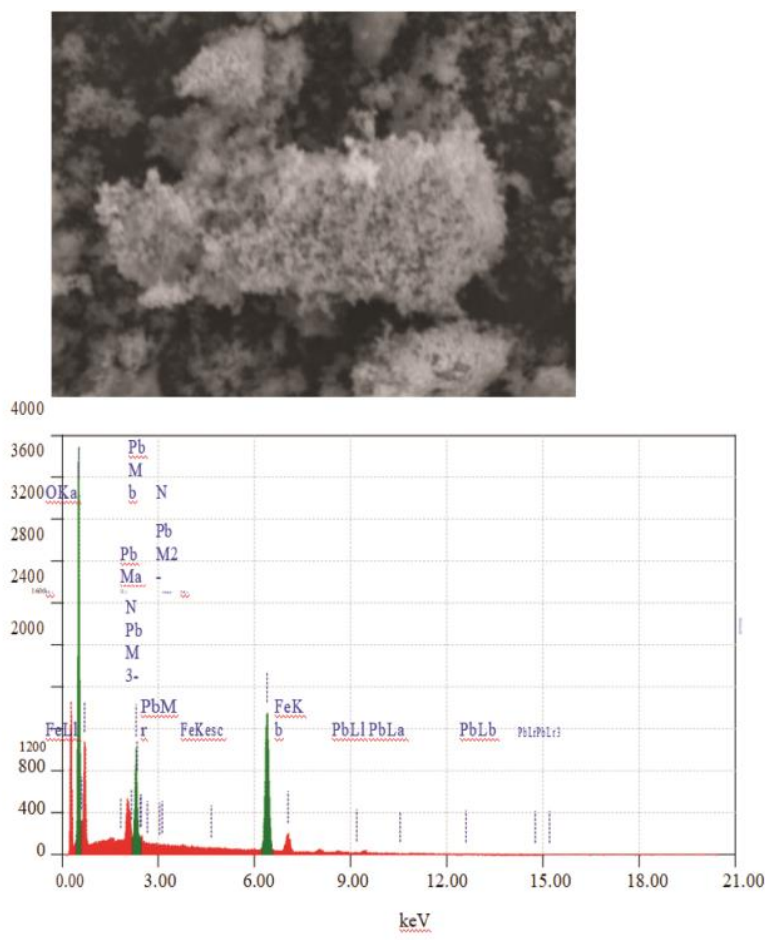

\begin{tabular}{|crr|}
\hline Element & $(\mathrm{keV})$ & Mass \\
$\mathrm{O}$ & & 28.70 \\
$\mathrm{~S} \mathrm{~K}$ & 2.307 & 7.25 \\
$\mathrm{Fe} \mathrm{K}$ & 6.398 & 61.63 \\
$\mathrm{~Pb} \mathrm{M}$ & 2.342 & 2.42 \\
Total & & 100.00 \\
\hline
\end{tabular}

Figure 3. SEM-EDX data of the solid resulted from photo-Fenton process of $\mathrm{Pb}^{2+}$

\subsection{The influence of the $\mathrm{H}_{2} \mathrm{O}_{2}$ concentration}

$\mathrm{H}_{2} \mathrm{O}_{2}$ amount is also a critical variable in the photoFenton's process that needs to be studied and optimized (Kavitha and Palanivelu, 2005). From Figure 4. it is observed that the improvement of the effectiveness of the $\mathrm{Pb}$ (II) removal is resulted, when the concentration of $\mathrm{H}_{2} \mathrm{O}_{2}$ is increased (the concentration of $\mathrm{Fe}^{2+} 10 \mathrm{mmol} / \mathrm{L}$, $\mathrm{pH} 3$ and the reaction time $90 \mathrm{~min}$, were maintained to be constant). Increasing $\mathrm{H}_{2} \mathrm{O}_{2}$ concentration produces more number of $\mathrm{OH}$ radicals, which enhances the oxidation process of $\mathrm{Pb}(\mathrm{II})$ ions. 


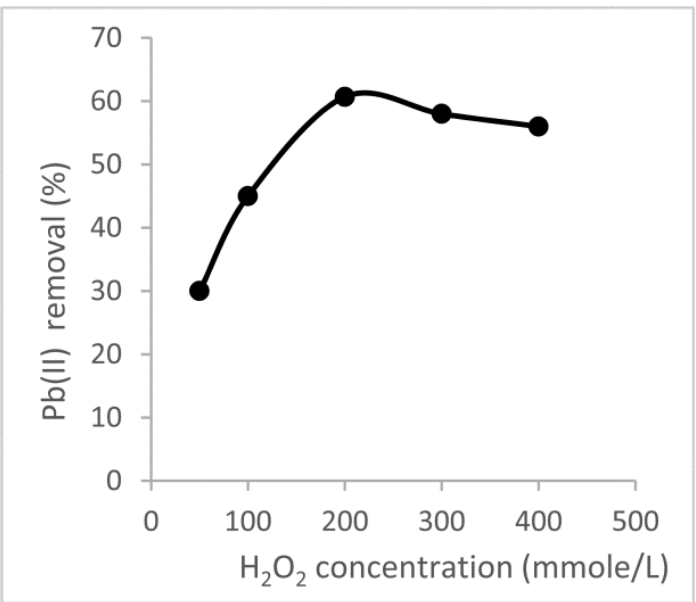

Figure 4. The influence of $\mathrm{H}_{2} \mathrm{O}_{2}$ concentration on the removal of $\mathrm{Pb}(\mathrm{II})$ in the solution

However the use of further larger concentration of $\mathrm{H}_{2} \mathrm{O}_{2}$ shows an opposite effect. The excess $\mathrm{H}_{2} \mathrm{O}_{2}$ can act as a scavenger of $\mathrm{OH}$ radicals. The reactions of the scavenging $\mathrm{OH}$ radical by the excessive $\mathrm{H}_{2} \mathrm{O}_{2}$ is presented as reaction (9) that reveals water and $\mathrm{HO}_{2}$ radicals (Kavitha and Palanivelu, 2004; Zazouli et al., 2012; Azhdarpoor et al., 2015; Wahyuni et al., 2016; Shaban et al., 2017; Ali and Ameta, 2013)

$$
\begin{aligned}
& \mathrm{H}_{2} \mathrm{O}_{2}+{ }^{\circ} \mathrm{OH} \rightarrow \mathrm{H}_{2} \mathrm{O}+\mathrm{HO}_{2} \cdot \\
& \mathrm{HO}_{2}^{\cdot}+\mathrm{Fe}^{3+} \rightarrow \mathrm{O}_{2}+\mathrm{Fe}^{2+}+\mathrm{H}^{+}
\end{aligned}
$$

Reaction (9) should deplete the amount of $\mathrm{OH}$ radicals, that must be followed by the less effective of the $\mathrm{Pb}$ (II) photooxidation.

\subsection{The influence of reaction $\mathrm{pH}$}

$\mathrm{pH}$ is one of the major factors limiting the performance of the photo-Fenton process. The solution $\mathrm{pH}$ plays role in controlling the species of ferrous and the stability of hydrogen peroxide (Kavitha and Palanivelu, 2005). It is seen in the Figure 5 that alteration $\mathrm{pH}$ results in the various photooxidation efficiency.

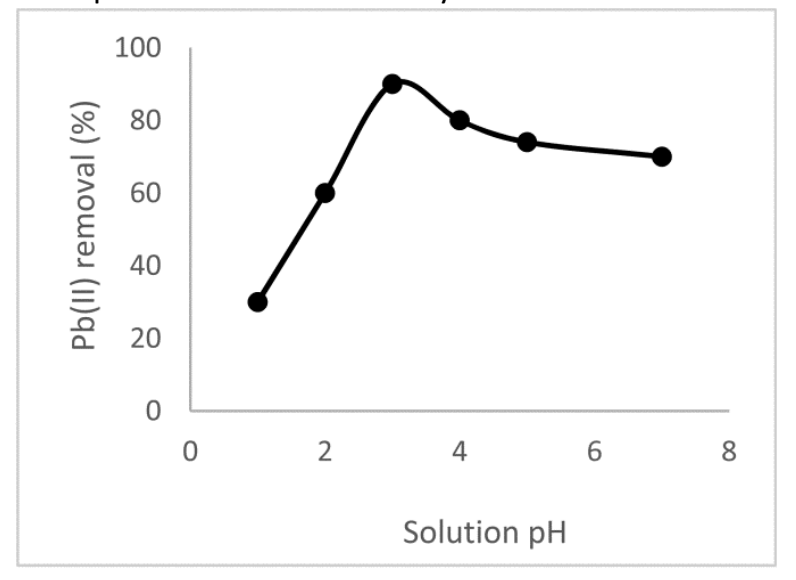

Figure 5. The influence of solution $\mathrm{pH}$ on the removal of $\mathrm{Pb}$ (II) in the solution

In more detail, increasing $\mathrm{pH}$ can enhance the photooxidation that reaches maximum level at $\mathrm{pH} 3$, and the photooxidation slightly goes down with the increase of $\mathrm{pH}$.
At low level of $\mathrm{pH}, \mathrm{Fe}^{2+}$ forms a stable complex with $\mathrm{H}_{2} \mathrm{O}_{2}$, which neutralizes the iron catalyst and significantly reduces the $\mathrm{Pb}$ (II) oxidation (Wahyuni et al., 2016). The other reason presented by Shaban et al. (Çiner, 2017), that is in the low $\mathrm{pH}$, hydrogen ion $\left(\mathrm{H}^{+}\right)$are present in large amount, that can protonate of $\mathrm{H}_{2} \mathrm{O}_{2}$ to form protonated hydrogen peroxide or $\mathrm{H}_{3} \mathrm{O}_{2}{ }^{+}$. The protonated hydrogen peroxide inhibits the hydroxyl radical generation. This results in small number of $\mathrm{OH}$ radicals, that further leads to the lower photooxidation.

Increasing $\mathrm{pH}$ up to 3 , the complex of $\mathrm{Fe}^{2+}$ with $\mathrm{H}_{2} \mathrm{O}_{2}$ should be decomposed allowing $\mathrm{Fe}^{2+}$ to catalyze $\mathrm{H}_{2} \mathrm{O}_{2}$ maximally, and much hydroxyl radicals can be provided. In addition, at higher $\mathrm{pH}$ the protonation of $\mathrm{H}_{2} \mathrm{O}_{2}$ should also decrease, that promote more hydroxyl radical formation. The more number of the radicals provided, should raise the photooxidation.

At $\mathrm{pH}$ higher than 3, the larger number of hydroxide ion $\left(\mathrm{OH}^{-}\right)$are available, facilitating $\mathrm{Fe}^{+3}$ ions resulted from $\mathrm{Fe}^{+2}$ ions, to deposit as $\mathrm{Fe}(\mathrm{OH})_{3}$. As a consequence, the sufficient $\mathrm{Fe}^{2+}$ catalyst does not remain in the solution. This causes lower decomposition of $\mathrm{H}_{2} \mathrm{O}_{2}$ and reduces the efficiency of the Fenton's process. Also, studies have shown that oxidative potential of $\mathrm{OH}$ radicals decreases (Zazouli et al., 2012; Shaban et al., 2017; Çiner, 2017; Ali and Ameta, 2013) and hydrogen peroxide has less stability (Çiner, 2017) with increasing $\mathrm{pH}$. All the previous conditions will result in decreasing the produced hydroxyl radicals, and hence the $\mathrm{Pb}^{2+}$ photooxidation.

It is clear that an essential characteristic of the Fenton's process is that $\mathrm{pH}$ in the acidic range strongly favors oxidation, that can avoid the $\mathrm{Fe}^{3+}$ from precipitation process. The finding optimum $\mathrm{pH}(=3)$ agrees with several studies already carried out (Kavitha and Palanivelu, 2004, 2005; Huang et al., 2010; Kusi et al., 2006; Azhdarpoor et al., 2015; Shaban et al., 2017; Ali and Ameta, 2013). But the optimum $\mathrm{pH}$ values that were slightly lower (Wahyuni et al., 2016) or higher than 3 (Çiner, 2017) in the range of 2.0 and 4.5 were also observed (Zazouli et al., 2012).

\subsection{The influence of the $P b^{2+}$ initial concentration}

In order to find out the capacity of the photo-Fenton in oxidation of $\mathrm{Pb}^{2+}$, the initial concentration of $\mathrm{Pb}^{2+}$ was varied and the result is presented as Figure 6 . The figure depicts that increasing initial $\mathrm{Pb}^{2+}$ concentration can enhance sharply the amount of $\mathrm{Pb}^{2+}$ oxidized, but further increase of the initial concentration, the slight increase is observed. The condition of low concentration of $\mathrm{Pb}^{2+}$ (5-10 $\mathrm{mg} / \mathrm{L})$ with a lot of $\mathrm{OH}$ radicals, promotes very effective oxidation, resulting in the complete oxidation (>90\%). Increasing initial $\mathrm{Pb}^{2+}$ concentration can results in more effective collision between $\mathrm{OH}$ radicals with $\mathrm{Pb}^{2+}$ ions, that produce higher oxidation.

With very high concentration, much more $\mathrm{Pb}^{2+}$ ions are available for oxidation, that may start act as a filter for the incident light. This can inhibit the light intensity to reach at the reagents. As a result, a decrease in the rate of 
oxidation of $\mathrm{Pb}^{2+}$ was attributed. In addition, with high $\mathrm{Pb}^{2+}$ that are oxidized, the $\mathrm{OH}$ radicals become depleted that leads to the slower oxidation. This finding is consistence with that of found by Shaban et al. (Çiner, 2017) for dye photodegradation.

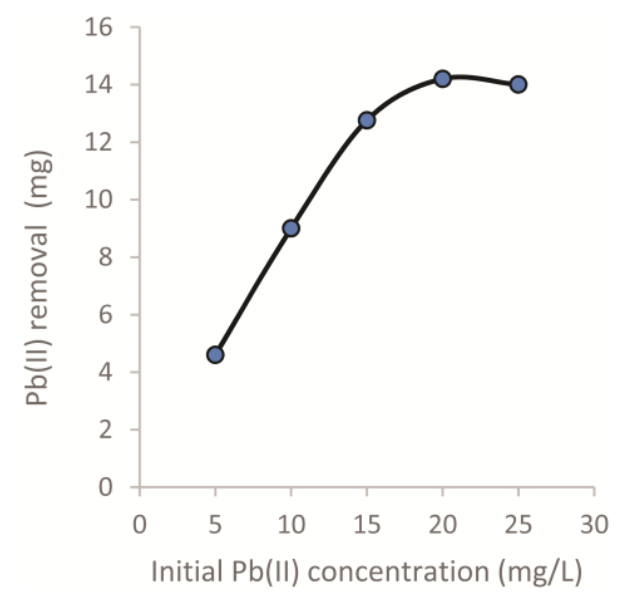

Figure 6. The effect of the initial $\mathrm{Pb}$ (II) concentration on the effectiveness of $\mathrm{Pb}^{2+}$ photo-oxidation

\subsection{The Influence of reaction time}

The reaction time also plays important role on the yields of the reaction, thereby it is important to be optimized. The influence of the reaction time is demonstrated by Figure 7. The expansion time up to 90 min can enhance of the photo-oxidation, but after $90 \mathrm{~min}$, the photo-oxidation does not depend on the reaction time. With the amount of $\mathrm{Fe}^{2+} 10$ mmole and $\mathrm{H}_{2} \mathrm{O}_{2} 200$ mmole, the longer of the reaction time can improve of the effectiveness of the interaction between $\mathrm{Fe}^{2+}$ and $\mathrm{H}_{2} \mathrm{O}_{2}$ and UV light with $\mathrm{H}_{2} \mathrm{O}_{2}$ that produces considerably amount of $\mathrm{OH}$ radicals (Babuponnusami and Muthukumar, 2014). The larger amount of $\mathrm{OH}$ radicals has promoted higher photo-oxidation of $\mathrm{Pb}^{2+}$ ions in the solution. The reaction time longer than $90 \mathrm{~min}$, the large amount of $\mathrm{PbO}_{2}$ solid has been produced that inhibit the light entering, accordingly the photo-oxidation does not change appreciably (Kavitha and Palanivelu, 2005; Tony and Bedri, 2014).

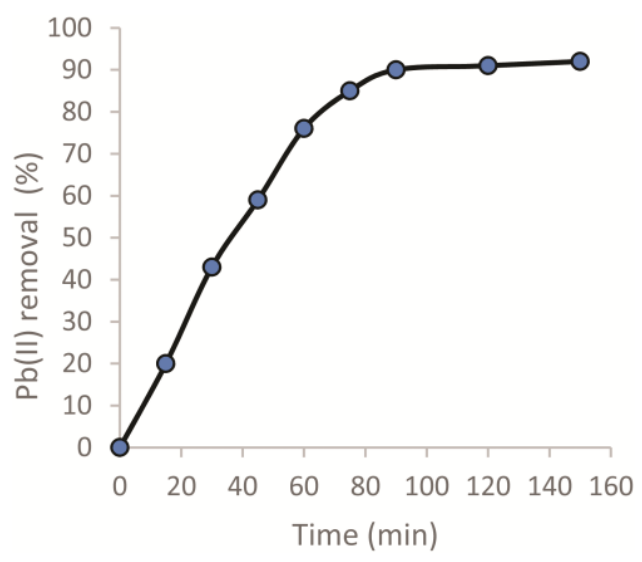

Figure 7. The influence of reaction time on the effectiveness of $\mathrm{Pb}^{2+}$ photo-oxidation

\subsection{Kinetic study}

The kinetic of photo-Fenton processes for oxidation of $\mathrm{Pb}^{2+}$ was studied to determine the reaction order and the constant of the reaction rate. In the process, the chemicals reacting were hydroxyl radicals formed from Fenton's agent assisted with UV light as oxidizing agent and $\mathrm{Pb}^{2+}$ as substrate in the solution. Consequently, the reaction rate should follow a second-order rate equation, that can be presented by equation (11):

$$
\mathrm{d}\left[\mathrm{Pb}^{2+}\right] / \mathrm{dt}=-\mathrm{k}\left[\mathrm{Pb}^{2+}\right]\left[{ }^{\circ} \mathrm{OH}\right]
$$

In the photo-Fenton reaction, the concentration of hydroxyl radicals is in excess, and during the reaction the concentration of the radicals may be constant (Kavitha and Palanivelu, 2005). Hence the equation of the reaction rate should be modeled as the pseudo first-order reaction following equation (12).

$$
\mathrm{d}\left[\mathrm{Pb}^{2+}\right] / \mathrm{dt}=-\mathrm{k}^{\prime}\left[\mathrm{Pb}^{2+}\right]
$$

The equation (12) can be derived into equation (13) as follow:

$$
\ln \left[\mathrm{Pb}^{2+}\right]_{0} /\left[\mathrm{Pb}^{2+}\right]_{\mathrm{t}}=-\mathrm{k}^{\prime} . \mathrm{t}
$$

With $\left[\mathrm{Pb}^{2+}\right]_{0}$ : initial concentration of $\mathrm{Pb}^{2+}$ in the solution, $\left[\mathrm{Pb}^{2+}\right]_{\mathrm{t}}$ : concentration of $\mathrm{Pb}^{2+}$ left in the solution after $t$ mins of the reaction, $t$ : period of the reaction time, and $k^{\prime}$ : rate reaction constant of pseudo first -order reaction.

The experimental serial data is plotted into the equation (13) and the curve resulted is displayed as Figure 8. The figure demonstrates the linear curve with the correlation factor $\left(r^{2}\right)$ is found about 0.98. It is obviously seen that the photo-oxidation of $\mathrm{Pb}^{2+}$ fits with the pseudo first -order reaction model. The same order of the photoFenton reaction has also been reported (Kavitha and Palanivelu, 2005; Tony and Bedri, 2014) for degradation of nitrophenols and phenol, respectively, by hydroxyl radicals formed by Fenton's agent. From the curve, the reaction rate constant $\left(k^{\prime}\right)$ can also be calculated, that is as high as $0.07 \mathrm{~min}^{-1}$.

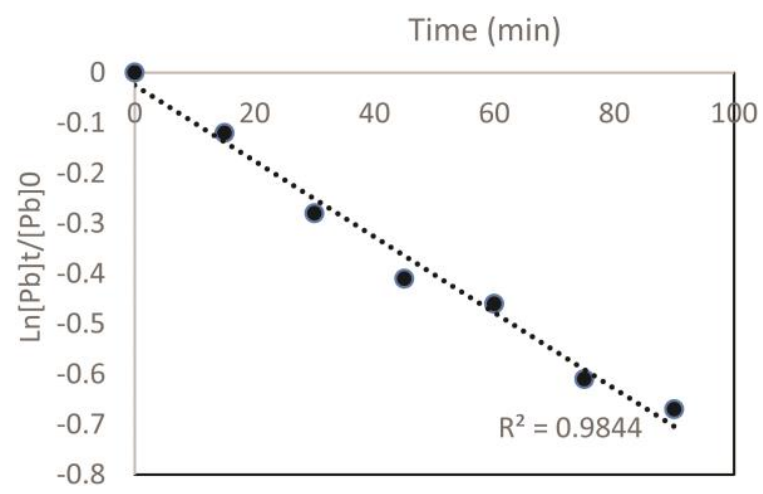

Figure 8. Pseudo first-order plot for $\mathrm{Pb}^{2+}$ oxidation by $\mathrm{OH}$ radicals

\section{Conclusions}

It can be concluded that by employing photo-Fenton process, the concentration of $\mathrm{Pb}^{2+}$ ions in the solution can be decreased due to the oxidation by hydroxyl radicals to 
form $\mathrm{PbO}_{2}$. The efficiency of $\mathrm{Pb}^{2+}$ photooxidation, in addition to be dependence on the concentrations of $\mathrm{Fe}^{2+}$ and $\mathrm{H}_{2} \mathrm{O}_{2}$ in the solution, and time, it is also controlled by the initial $\mathrm{Pb}^{2+}$ concentration and the reaction $\mathrm{pH}$. The maximum decreasing $\mathrm{Pb}^{2+}$ concentration, that is about $80 \%$, is obtained with the use of $\mathrm{Fe}^{2+} / \mathrm{H}_{2} \mathrm{O}_{2}$ mole ratio as $1 / 20$ at $\mathrm{pH} 3$ and $90 \mathrm{~min}$ of time, from $20 \mathrm{mg} / \mathrm{L}$ of the $\mathrm{Pb}^{2+}$ initial concentration in the solution. Furthermore, the oxidation of $\mathrm{Pb}^{2+}$ by $\mathrm{OH}$ radical generated by Fenton's agent is found to well fit with a pseudo-first order model with moderate rate.

\section{References}

Ajmal A., Majeed I., Malik R.N., Idriss H. and Nadeem M.A. (2014), Principles and mechanisms of photocatalytic dye degradation on $\mathrm{TiO}_{2}$ based photocatalysts: a comparative overview. RSC Advances, 4, 37003-37026.

Ali Y. and Ameta A. (2013), Degradation and decolouration of amaranth dye by photo-Fenton and Fenton reagents: a comparative study. International Journal of Chemical Sciences, 11(3), 1277-1285.

Asuquo E., Martin A., Nzerem P., Siperstein F. and Fan X. (2017), Adsorption of $\mathrm{Cd}(\mathrm{II})$ and $\mathrm{Pb}(\mathrm{II})$ from aqueous solution using mesoporous activated carbon adsorbent: equilibrium, kinetics and characterization studies. Journal of Environmental Chemical Engineering, 5, 679-698.

Ayoub A., Venditti R.A., Pawlak J.J., Salam A., Hubbe M.A. (2013), Novel hemicellulose-chitosan biosorbent for water desalination and heavy metal removal. ACS Sustainable Chemistry \& Engineering, 1, 1102-1109.

Azhdarpoor A., Hoseini R. and Dehghani M. (2015), Leaching Zn, $\mathrm{Cd}, \mathrm{Pb}$, and $\mathrm{Cu}$ from wastewater sludge using Fenton process. Journal of Health Sciences and Surveillance System, 3(4), 153-159.

Babuponnusami A. and Muthukumar K. (2014), A review on Fenton and improvements to the Fenton process for wastewater treatment. Journal of Environmental Chemical Engineering, 2, 557-572.

Chen D. and Ray A.K. (2001), Removal of toxic metal ions from wastewater by semiconductor photocatalysis, Chemical Engineering Science, 56(2001), 1561-1570.

Chen H., Zhao J., Dai G., Wu J. and Yan W. (2010), Adsorption characteristic of $\mathrm{Pb}$ (II) from aqueous solution onto a natural biosorbent fallen Cinnamomum camphora leaves. Desalination, 262, 174-182.

Choquette-Labbé M., Shewa W.A., Lalman J.A. and Shanmugam S.R. (2014), Photocatalytic degradation of phenol and phenol derivatives using a nano- $\mathrm{TiO}_{2}$ catalyst: integrating quantitative and qualitative factors using response surface methodology. Water, 6, 1785-1806.

Çiner F. (2017), Application of Fenton reagent and adsorption as advanced treatment processes for removal of Maxilon Red GRL. Global NEST Journal, 20(1), 1-6.

Dariani R.S., Esmaeili A., Mortezaali A. and Dehghanpour S. (2016), Photocatalytic reaction and degradation of methylene blue on $\mathrm{TiO}_{2}$ nano-sized particles. Optik, 127, 7143-7154.

Fujishima A., Rao T.N. and Tryk D.A. (2000), Titanium dioxide photocatalysis. Journal of Photochemistry and Photobiology, C: Photochemistry Reviews, 1, 1-21.
Gautam A., Kshirsagar A., Biswas R., Banerjee S. and Khann P.K. (2016), Photodegradation of organic dyes based on anatase and rutile $\mathrm{TiO}_{2}$ nanoparticles, RSC Advances, 6, 2746-2759.

Grabowska E., Reszczynska J. and Zaleska A. (2012), Mechanism of phenol photodegradation in the presence of pure and modified- $\mathrm{TiO}_{2}$ : a review. Water Research, 46, 5453-5471.

Harrison R.M. and Laxen D.P.H. (1981), Lead Pollution: Causes and Control. Chapman and Hall.

Huang Y.-H., Huang Y.-J., Tsai H.-C. and Chen H.-T. (2010), Degradation of phenol using low concentration of ferric ions by the photo-Fenton process. Journal of the Taiwan Institute of Chemical Engineers, 41, 699-704.

Joseph B.A. and Katoch S.S. (2016), Study of Landfill Leachate Treatment Using Photo-Fenton Process - A Review, Proceeding of IRF International Conference, 24th January 2016, New Delhi India, ISBN: 978-93-85973-09-3, pp. 1-5.

Kavitha V. and Palanivelu K. (2004), The role of ferrous ion in Fenton and photo-Fenton processes for the degradation of phenol. Chemosphere, 55, 1235-1243.

Kavitha V. and Palanivelu K. (2005), Degradation of nitrophenols by Fenton and photo-Fenton processes. Journal of Photochemistry and Photobiology A: Chemistry, 170, 83-95.

Kusi H., Koprivanac N. Bozi A.L., and Selanec I. (2006), Photoassisted Fenton type processes for the degradation of phenol: a kinetic study. Journal of Hazardous Materials $B$, 136, 632-644.

Mahmoud M.E., Abdou A.E.H. and Ahmed S.B. (2016), Conversion of waste styrofoam into engineered adsorbents for efficient removal of cadmium, lead and mercury from water. ACS Sustainable Chemistry \& Engineering, 4, 819-827.

NRC Committee on Lead in the Human Environment. (1980), Lead in the Human Environment. National Academy of Sciences, Washington DC.

Reza K.M., Kurny A.S.W. and Gulshan F. (2017), Parameters affecting the photocatalytic degradation of dyes using $\mathrm{TiO}_{2}$ : a review. Applied Water Science, 7, 1569-1578.

Shaban M., Abukhadra M.R., Ibrahim S.S., and Shahien M.G. (2017), Photocatalytic degradation and photo-Fenton oxidation of Congo red dye pollutants in water using natural chromite-response surface optimization. Applied Water Science, 7, 4743-4756.

Shukla S.S., Dorris K.L. and Chikkaveeraiah B.V. (2009), Photocatalytic degradation of 2,4-dinitrophenol. Journal of Hazardous Materials, 164(2009), 310-314.

Soliman A.M., Elwy H.M., Thiemann T., Majedi Y., Lebata F.T. and Rawashdeh N.A.F. (2016), Removal of $\mathrm{Pb}$ (II) from aqueous solution by sulfuric acid treated-palm tree leaves. Journal of The Taiwan Institute of Chemical Engineers, 58, 264-273.

Tanaka K., Harada K. and Murata S. (1986), Photocatalytic deposition of metal ions onto $\mathrm{TiO}_{2}$ powder. Solar Energy, 36, 159-161

Tony M.A. and Bedri Z. (2014), Experimental Design of PhotoFenton Reactions for the Treatment of Car Wash Wastewater Effluents by Response Surface Methodological Analysis, Hindawi Publishing Corporation, Advances in Environmental Chemistry, 2014, p. 8.

Turki A., Guillard C., Dappozze F., Ksibi Z., Berhaultb G., and Kochkar H. (2015), Phenol photocatalytic degradation over anisotropic $\mathrm{TiO}_{2}$ nanomaterials: kinetic study, adsorption isotherms and formal mechanisms. Applied Catalysis B: Environmental, 163, 404-414. 
Wahyuni E.T., Aprilita N.H. Hatimah H., Wulandari A.M. and Mudasir. (2015), Removal of toxic metal ions in water by photocatalytic method. American Chemical Science Journal, 5(2), 194-201.

Wahyuni E.T., Roto R., Sabrina M., Anggraini V., Leswana N.F. and Vionita A.C. (2016), Photodegradation of detergent anionic surfactant in wastewater using $\mathrm{UV} / \mathrm{TiO}_{2} / \mathrm{H}_{2} \mathrm{O}_{2}$ and $\mathrm{UV} / \mathrm{Fe}^{2+} / \mathrm{H}_{2} \mathrm{O}_{2}$ processes. American Journal of Applied Chemistry, 4(5), 174-180.

Yao S., Zhang J., Shen D., Xiao R., Gu S., Zhao M. and Liang J. (2016), Removal of $\mathrm{Pb}$ (II) from water by the activated carbon modified by nitric acid under microwave heating. Journal of Colloid and Interface Science, 463, 118-127.

Yuvaraja G., Krishnaiah N., Subbaiah M.V. and Krishnaiah A. (2014), Biosorption of $\mathrm{Pb}$ (II) from aqueous solution by Solanum melongena leaf powder as a low-cost biosorbent prepared from agricultural waste. Colloids and Surfaces $B$ : Biointerfaces, 114, 75-81.

Zazouli M.A., Yousefi Z., Eslami A. and Ardebilian M.B. (2012), Landfill leachate treatment by Fenton, photo-Fenton and Fenton-like processes: effect of some variables. Iranian Journal of Environmental Health Science \& Engineering, 9(1), 3-10.

Zuo R., Du G., Zhang W., Liu L., Liu Y., Mei L and Zhaohui Li Z. (2014), Photocatalytic Degradation of Methylene Blue Using $\mathrm{TiO}_{2}$ Impregnated Diatomite, Hindawi Publishing Corporation, Advances in Materials Science and Engineering, 2014, p. 7. 